\title{
PREDICTION FINANCIAL STABILITY OF ROMANIAN PRODUCTION COMPANIES THROUGH ALTMAN Z-SCORE
}

\author{
Anna Siekelova $^{1, a,{ }^{*}, \text { Erika Kovalova }}{ }^{2, b}$ and Florin Cristian Ciurlău ${ }^{3, c}$ \\ ${ }^{1}$ Department of Economics, Faculty of Operation and Economics of Transport and Communications, \\ University of Zilina, Univerzitna 1, 01026 Zilina, Slovak Republic \\ ${ }^{2}$ Department of Economics, Faculty of Operation and Economics of Transport and Communications, \\ University of Zilina, Univerzitna 1, 01026 Zilina, Slovak Republic \\ ${ }^{3}$ The Faculty of Finance, Banking and Accountancy, "Dimitrie Cantemir" Christian University, \\ Bucharest, Romania, 176, Splaiul Unirii, District 4, Bucharest, Romania

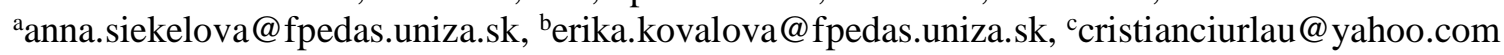 \\ *Corresponding author
}

Cite as: SIEKELOVA, A., KOVALOVA, E., CIURLÄU, C.F. (2019). Prediction financial stability of Romanian production companies through Altman Z-score, Ekonomicko-manazerske spektrum, 13(2), 89-97.

Available at: dx.doi.org/10.26552/ems.2019.2.89-97

\begin{abstract}
Nowadays, there is a much higher demand for financial and economic analyses in companies that help to face the challenges they face. The analysis is a tool for research, and evaluation of business transformation processes, conditions under which they take place. It also examines the impacts and causal relationships that take place here. Under the current economic conditions, it is necessary to apply new adequate methods in corporate governance that meet market needs and requirements. Prognosis of the development of the financial situation of the company, i.e., the forecast of its future solvency, or insolvency, is based on the evaluation and interpretation of the results achieved today. Financial analysis of the company plays a vital role. The main aim of the research paper is to predict the financial health of the company using Altman's Z score. The work consists of the theoretical part of the financial-economic analysis. In the second chapter, we defined the method and indicators by which we will analyse the selected production companies in Romania. We managed to obtain data from 105 manufacturing companies that have been on the market for at least five years for the analysis, and we focused on the last three years of their activity using Altman's Z score. In the results of the work, we specifically evaluated the financial health of the company using the chosen method. At the end of the paper, we generally evaluated the achieved results by analysis. All the data used in the processing were extracted from professional book literature and provided corporate resources, especially from the balance sheet and profit and loss account.
\end{abstract}

Keywords: Altman Z-score, bankruptcy, insolvency, financial health, financial analysis

JEL Classification: C53, G33, C58

\section{Introduction}

Now, there is a much higher demand for financial and economic analyses in companies that help to face the challenges they face. The results of the financial analysis are of interest to many entities that are part of the business environment, Bandyopadhyay (2006). In particular, it is banks that provide financial resources for companies or are prospective investors, shareholders who are interested in the current situation in the business management and its future 
development. But the company itself is involved in the outcome of the analysis because it can help it to develop its business further and produce more profits, in accordance with Grice and Ingram (2001), Son et al. (2019) and Buc and Kliestik (2013).

The market economy is a dynamic space designated by the emergence but also the extinction of many business entities. The financial problems of one business entity may adversely affect business entities that work closely with it, which may have a contrary socio-economic impact Hillegeist et al. (2004). A way to prevent business failure is to warn it in time. The issue of early warning systems deals with ex-ante financial analysis. Successful entrepreneurship is a long-term process beginning with an idea, the subsequent establishment of a company, building a market position, and maintaining its position Altman et al. (2017). During its existence, a business must take care of its health. Monitoring of the financial health of enterprises is carried out mainly by financial analysis. Financial analysis is a tool that allows you to know and explain past, present, and, using a suitable methodology, to predict future phenomena. The financial analysis dealing with predicting future aspects is called ex-ante financial analysis according to Almamy et al. (2016) and Cichocki and Unbehaven (1993). Regardless of where the incentive for financial analysis originates, the instruments used are mostly the same. The essential tool is the calculation and interpretation of appropriately selected financial indicators. Suitably used tools can answer a large number of questions about the financial health of a business Kingyens et al. (2016).

\subsection{Financial health and signals accompanying the financial difficulties}

The financial analysis aims to know financial health, identify weaknesses that lead to problems, and identify the strengths on which a business could build, Fedorova et al. (2013). According to Zhang et al. (1999), the financial analysis aims to assess the financial situation (financial health) of an enterprise and to determine which factors and with what intensity they were involved in shaping the financial situation. What requires systematizing the factors and knowing the nature of their actions. Given the quality of their activities, the relevant factors can be divided into two groups.' Since the aim of the present work is also the construction of models for the timely prediction of threats to financial health, i.e. a warning to prevent possible insolvency and subsequent bankruptcy, we pay attention to several indicators of bad financial health $\mathrm{Ng}$ et al. (2011).

We consider the level of indebtedness as a warning signal. High indebtedness of businesses can cause problems due to high-interest rates and the associated cash outflows, leading to subsequent financial difficulties, Leland and Toft (1996). In our opinion, we should also pay due attention to Cash Flow, which, unlike profit, examines the real state of cash. It should be borne in mind that even profitable companies may have negative Cash Flow values, which in the long run may lead to debt and financial difficulties. We have therefore selected the indicators for assessing financial health based on general assumptions and that the financial risk is mostly due to low profitability, low liquidity, and high indebtedness, Min and Lee (2005) and Wu et al. (2007).

\subsection{Data sources for financial analysis}

An essential resource for carrying out the financial analysis is the accounting records of the company, thanks to which the business manager can examine financial ratios, in particular, indicators of liquidity, activity, indebtedness, market value, and profitability. There are also several problems associated with financial statements. Authors Bielecki and Rutkowski (2013), Ho et al. (2013) and Szetela et al. (2016) state that the assumption of a fair and truthful description of a company's financial situation often influences the 'creative accounting' of the 
company's management, especially just before the company's financial failure. Another problem, especially in the analysis of small and medium-sized enterprises, maybe the missing data for the calculation of some financial ratios, Calabrese et al. (2016). This problem can cause a narrow focus of business activity - business orientation mainly on production or provision of services and the absence of broad financial management activities. Despite these shortcomings, we believe that under the conditions of the Romanian economy, financial statements are the best means of obtaining information in a broader number of businesses. The reason is mainly due to the underdeveloped capital market and the impossibility of gathering market information on such a large number of enterprises as in the financial statements Atiya (2001).

\section{Methodology}

Several authors admit that the financial analysis process can be broken down into the following successive stages:

Calculation of financial ratios. Thanks to the possibility to get a quick and inexpensive picture of the essential financial characteristics of a company, financial ratios are the most popular and the most popular method of financial analysis. The disadvantage of financial ratios is the low ability to explain phenomena. Next is a comparison of indicators with average (or extreme) indicators for the business sector concerned or examining the development of selected business indicators over time. Popular is also analysing the relationships between financial ratios and draft measures as well.

The starting point for almost all predictive models is that there are certain anomalies in the company sometime before the crisis, which contain symptoms of future problems and which are characteristic of endangered enterprises, Chen (1993). The time period for which it is worth constructing a model depends mostly on the size of the business. We think that a period of one year is sufficient for micro-enterprises to develop an appropriate refinancing plan and apply its tools to maintain its existence. For small and medium-sized enterprises, we consider the ideal predictive capability of the model for two years, as theoretically, they may find themselves in a situation where they have to monetize certain items of fixed assets and appropriately invest the funds thus obtained, which may take a longer time.

There are many divisions of prediction models in the literature that differ from one author to another. For example, Chen (1993) report the division of prediction models according to their purpose into credit and bankruptcy models. The methods of one-dimensional analysis try to find a simple quantitative characteristic that would collectively describe the financial and economic situation of the company and would be able to distinguish relatively reliably from the companies with financial risk to the prosperous ones. The choice of a single financial ratio indicator is usually preceded by an analysis that allows us to select an indicator based on a specific criterion, in our case, a distinction between healthy and financially vulnerable enterprises. An example of such an analysis may be factor analysis. One-dimensional prediction models include, for example, Beaver (1966) one-dimensional discriminant analysis (dichotomous classification test). However, the one-dimensional discriminatory analysis has not gained a more prominent position among the prediction methods because its biggest drawback is its ambiguity. The ability to evaluate a business based on only one indicator, with many indicators having good ability to forecast financial developments only in conjunction with other indicators, leading to two and multidimensional discrimination analysis, find Shin et al. (2005).

When using multivariate analysis, in literature, we often encounter also called mathematicalstatistical methods of prediction, Chung et al. (2016). Since the model, in this case, is 
constructed based on data and not based on expert evaluation, we can also mark them as exact. Historically, linear discrimination analysis and logistic regression have been most commonly used in their construction, Gavurova et al. (2017). Of course, we have a large number of other methods that can be used to construct a model for predicting the level of the financial health of an enterprise. In addition to the aforementioned linear discriminant analysis and logistic regression, frequently used methods are quadratic discriminant analysis, decision trees, forests, neural networks, fuzzy classifiers, and the like.

In this research paper, we applied the Altman Z-score model for manufacturing companies in Romania. This author first quantified the multidimensional discriminatory function. Altman analyzed a group of 66 businesses, half of which were prosperous, the other non-prosperous. The statistical analysis found that the following indicators are the best evidence of the financial situation and its future development:

The Altman Z-Score Model: $\mathrm{Z}=1.2 \mathrm{X} 1+1.4 \mathrm{X} 2+3.3 \mathrm{X} 3+0.6 \mathrm{X} 4+1 \mathrm{X5}$

Where

$\mathrm{X} 1$ = Working Capital / Total Assets,

X2 = Retained Earnings / Total Assets,

X3 = Earnings Before Interest and Taxes / Total Assets,

X4 = Market Value of Equity / Total Liabilities,

X5 $=$ Sales/ Total Assets.

The author also set the boundaries of the bands by which the future is predicted. If it is:

Z> 2.99 the company's financial situation is good,

$\mathbf{1 . 8 1}<\mathrm{Z}<=\mathbf{2 . 9 9}$ non-matched results area (grey zone), bankruptcy is possible,

$\mathrm{Z}<\mathbf{1 . 8 1}$ the financial situation is critical; bankruptcy is very likely.

By comparing selected intervals over several years, it can even have a very significant impact on the aspirations, mentality, or endurance of the actors of change. After its application, it is possible to see precisely what exactly changes or implemented solutions mean for the company operation. Through Altman's analysis, the financial manager gets a clear view of the effectiveness of his answers. Bankruptcy model based on ratios uses primarily in financial analysis. This model aims to express the financial condition of the company using a single value, which evaluates the probability of the company going into bankruptcy in the medium term. This value becomes a kind of trustworthiness index - the health of the company.

\section{Results}

Altman Z - coefficient addresses the financial situation of the company for the period under review. Table 1 shows that, based on this model, 37 of the 105 Romanian manufacturing companies would be financially stable. But in the grey zone, the number would be 39 , and the undertaking in danger of insolvency is 29 . The overall development over the last five years has not changed. The number of businesses in the grey zone has increased, and the risk of bankruptcy in the past has decreased. It is important to note that each business is specific and may deviate. 
Table 1: Number of enterprises and their financial health per year in \%

\begin{tabular}{l|lllll}
\hline & $\mathbf{2 0 1 4}$ & $\mathbf{2 0 1 5}$ & $\mathbf{2 0 1 6}$ & $\mathbf{2 0 1 7}$ & $\mathbf{2 0 1 8}$ \\
\hline $\mathrm{Z}>2.99$ & $40 \%$ & $37 \%$ & $36 \%$ & $36 \%$ & $35 \%$ \\
$1.81<\mathrm{Z}<=2.99$ & $28 \%$ & $19 \%$ & $36 \%$ & $31 \%$ & $37 \%$ \\
$\mathrm{Z}<1.81$ & $32 \%$ & $44 \%$ & $28 \%$ & $33 \%$ & $28 \%$
\end{tabular}

Source: Own processing

Figure 1 shows graphically how the financial health of the companies surveyed has evolved over five years. There are two lines. The top line means that the businesses above it are financially stable. Enterprises that are between two lines are in the so-called grey zone, and the companies listed below the bottom line are in an unfavourable financial situation and are at risk of bankruptcy.

Figure 1: Development of the financial health of manufacturing companies in Romania in 2016

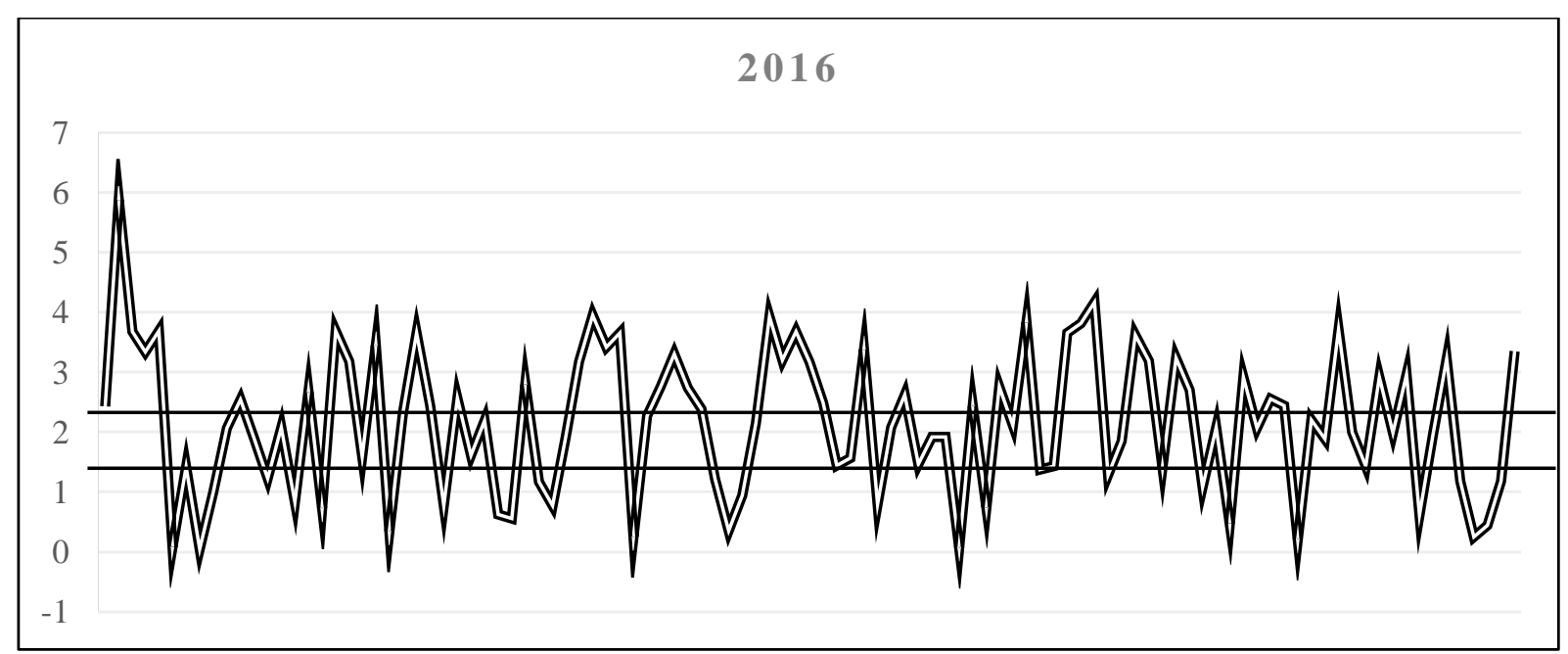

Source: own processing

In Figure 2, we can detect the development of financial health, where we classify 38 companies as financially stable companies, in the grey zone 33 and in a company that is threatened with bankruptcy, even 34 companies.

Figure 2: Development of the financial health of manufacturing companies in Romania in 2017

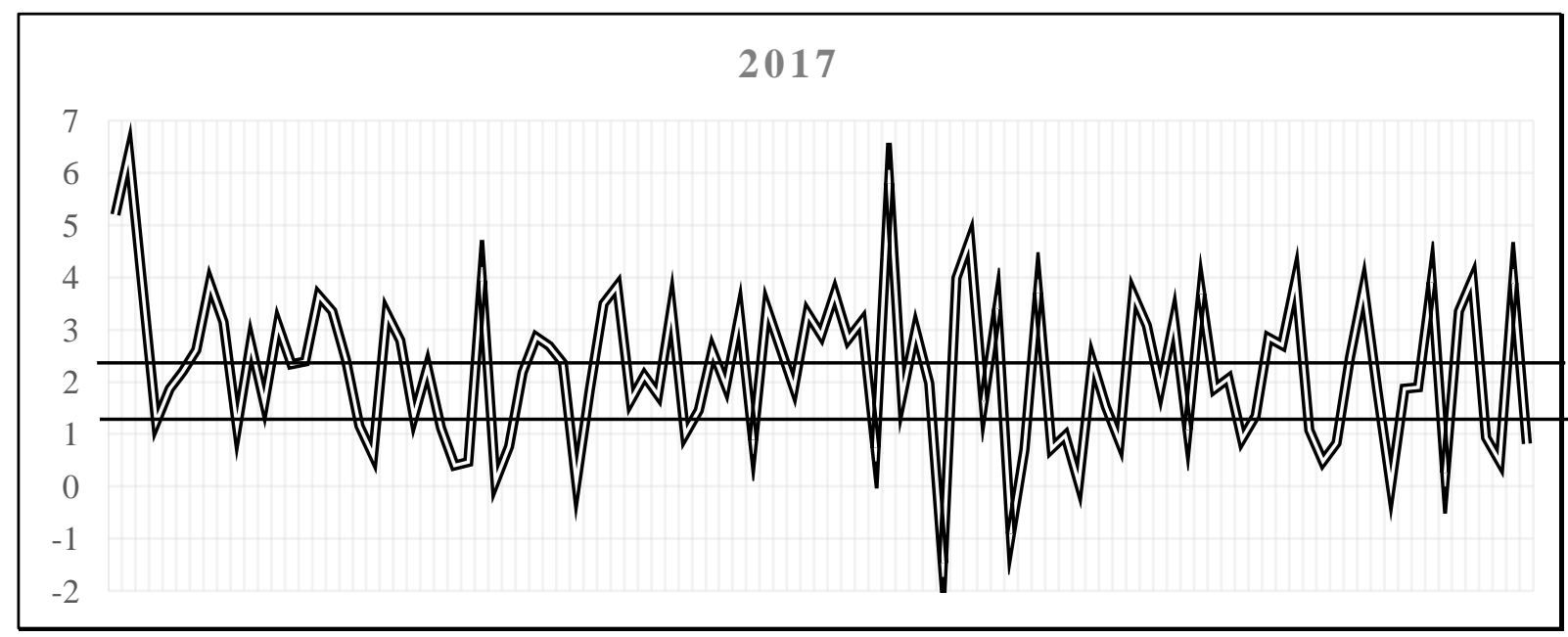

Source: Own processing 
Figure 3 shows the development again, and compared to the previous year, this time, there is one financially stable company less. A total of 39 enterprises belong to the grey zone, and the rest is classified as a financially unstable enterprise.

Figure 3: Development of the financial health of manufacturing companies in Romania in 2018

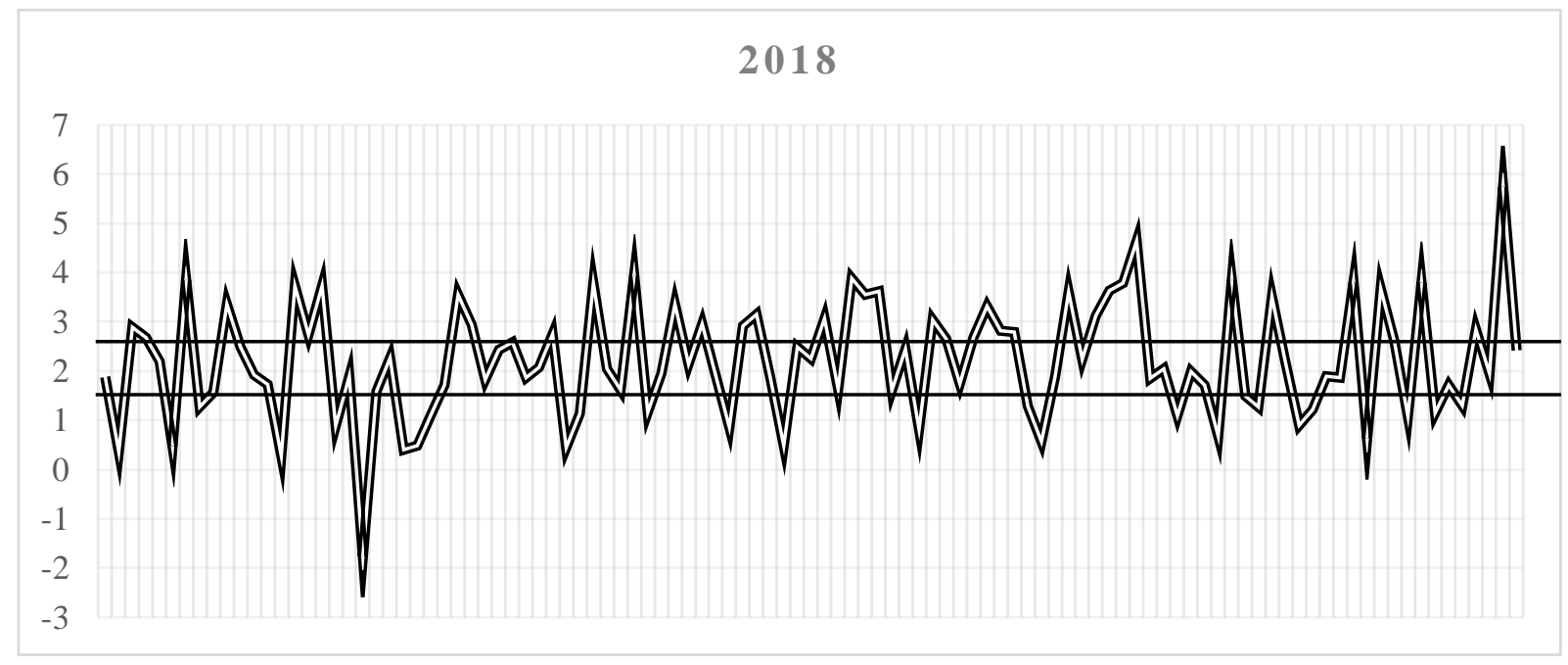

Source: Own processing

In 2015, the Z-score value was the worst in the period under review, this could have led to a negative pre-tax profit for that year, and the company was in a critical situation. As part of the overall assessment, this prediction model evaluates the analysed enterprise as being in the grey zone of non-reserved results. So, he joined the zone, which suggests that the company would prosper, but also that he is at risk of bankruptcy.

\section{Discussion}

At present, it is necessary to use predictive methods of financial-economic analysis, currently, the most widespread and most used predictive method of financial-economic analysis within the industry, representing a representative sample of the manufacturing sector, is Altman's methodology. Of course, problems encountered in the implementation of predictive methods of financial analysis can be attributed to the predictive techniques mentioned by the Altman methodology. It is necessary to improve continually, adapt, and approximate individual newly developed predictive methods of financial analysis to the specific needs of their endusers. This should include, in particular, the simplification of index calculation, the refinement of the rating scale, the reduction of input requirements for the use of predictive methods of financial-economic analysis and, last but not least, the improvement of business health, achieving the highest accuracy of business differentiation and achieving an in-depth, comprehensive view.

As can be seen, these facts will need to be changed and improved to make full use of the predictive methods of financial analysis within the financial management of companies in Romania. Nowadays, better quality and fuller use of predictive methods of financial-economic analysis in the financial management of companies is prevented both by external and internal factors (corporate staff, own company organization, level of technical equipment of the company such as computer equipment, level of information and communication technologies).

To improve the factor's condition, external and internal, it is necessary to work further to this extent. The improvement of internal factors (in-company) remains within the full competence of individual entities of the Romanian business sector (companies). It will be more challenging 
to correct the external factor represented by the level of business and market environment in Romania, as it is based on prosperity, economic, and economic factors and indicators of the whole state, not only on the (companies, institutions).

Since the spectrum of already existing predictive methods of financial analysis is relatively broad, it is necessary to develop an algorithm. A computer program or specialized software methods of financial-economic analysis for their effective and meaningful practical use within the financial management of industrial companies. The development of a selection algorithm and, subsequently, a computer program in the form of specialized software for the selection of a suitable predictive method of financial-economic analysis, which will be freely available on the Internet, is currently a big challenge.

\section{Conclusion}

The twentieth century has brought about the development of many advanced concepts and approaches, and it is now clear that we will not be able to withstand these approaches in the future. Ex-ante business analysis expresses the possibility to predict the development of the company's financial situation, its future solvency or insolvency. It is based on the evaluation and interpretation of the results achieved today and contains the symptoms of further development. They take the form of different levels and developments in the financial indicators used to convey an image of the company's financial condition. Today's dynamic evolution of economic structures suggests that only those who know promptly and flexibly one will have the right to exist. Such flexibility is conditional on the crucial information availability of real situations in which the company is located or information on the future development of the company.

Information on the actual case in which the company is located and information on the development of the company in the future is essential and relevant for the company, especially in terms of new business could get enough. Among the existing models used in practice, we verified the predictive abilities on our dataset for the Altman modified model from 1983 with an accuracy of $70.9 \%$. We created a database of 105 manufacturing companies and then applied the Altman model Z score. Subsequently, we evaluated the financial health of businesses and provided results. Companies must monitor their financial flows and attach importance to each model. The model does not determine financial health with complete confidence; Models need to be continuously verified, and it also depends on the character of the company because quantitative data are entering the analyses. There is no space for qualitative purposes. It is essential to define the factors affecting business health. Working capital, which is more difficult to quantify, can also have an enormous impact. This issue still requires a lot of attention and involvement of computer experts who could create software for more straightforward calculation and tracking of flows in the enterprise.

The demise of the company is endangered by management, employees, and external partners, who would all like to rely on financial analysis, in particular, to apply its predictive methods as an early warning tool. The warning should come in advance so that management can even try to prevent the bankruptcy and that the owners, creditors and business partners can protect themselves from adverse consequences.

The business system and its functioning express through a large number of financial and non-financial characteristics. The most concentrated image of the operation of the company is its image in the form of substantial data from basic financial statements (balance sheets and profit and loss accounts). The accounting view of an enterprise is a description of all financially expressed transactions that have taken place in a given enterprise in a given period, where all 
data are interconnected and form a system. This picture is not only a specialized financial perspective but, above all, also a corporate-wide view. Financial data (not only financial but also internal or managerial accounting) are the starting point for financial analysis.

\section{Acknowledgement}

The paper is an output of the science project VEGA 1/0428/17 Creation of new paradigms of financial management at the threshold of the 21 st century in conditions of the Slovak Republic.

\section{References}

Altman, E.I., Iwanicz-Drozdowska, M., Laitinen, E.K. \& Suvas, A. (2017). Financial distress prediction in an international context: A review and empirical analysis of Altman's Z-score model. Journal of International Financial Management \& Accounting, 28(2), 131-171.

Almamy, J., Aston, J. \& Ngwa, L. N. (2016). An evaluation of Altman's Z-score using cash flow ratio to predict corporate failure amid the recent financial crisis: Evidence from the UK. Journal of Corporate Finance, 36, $278-285$.

Atiya, A.F. (2001). Bankruptcy prediction for credit risk using neural networks: A survey and new results. IEEE Transactions on neural networks, 12(4), 929-935.

Bandyopadhyay, A. (2006). Predicting probability of default of Indian corporate bonds: Logistic and Z-score model approaches. The Journal of Risk Finance, 7(3), 255-272.

Bielecki, T.R. \& Rutkowski, M. (2013). Credit risk: Modeling, valuation and hedging. Springer Science \& Business Media.

Buc, D. \& Kliestik, T. (2013). Aspects of statistics in terms of financial modelling and risk. Proceeding of the 7th International Days of Statistics and Economics, Prague, Czech Republic: 215-224.

Calabrese, R., Marra, G. \& Angela Osmetti, S. (2016). Bankruptcy prediction of small and medium enterprises using a flexible binary generalized extreme value model. Journal of the Operational Research Society, 67(4), 604-615.

Chen, W.K. (1993). Linear Networks and Systems, Belmont, CA: Wadsworth.

Cichocki, A. \& Unbehaven, R. (1993). Neural Networks for Optimization and Signal Processing, 1st ed. Chichester, U.K.: Wiley.

Fedorova, E., Gilenko, E. \& Dovzhenko, S. (2013). Bankruptcy prediction for Russian companies: Application of combined classifiers. Expert Systems with Applications, 40(18), 7285-7293.

Gavurova, B., Packova, M., Misankova, M. \& Smrcka, L. (2017). Predictive potential and risks of selected bankruptcy prediction models in the Slovak business environment. Journal of Business Economics and Management, 18(6), 1156-1173.

Grice, J.S. \& Ingram, R.W. (2001). Tests of the generalizability of Altman's bankruptcy prediction model. Journal of Business Research, 54(1), 53-61.

Hillegeist, S.A., Keating, E.K., Cram, D.P. \& Lundstedt, K.G. (2004). Assessing the probability of bankruptcy. Review of accounting studies, 9(1), 5-34.

Ho, C.Y., McCarthy, P., Yang, Y. \& Ye, X. (2013). Bankruptcy in the pulp and paper industry: market's reaction and prediction. Empirical Economics, 45(3), 1205-1232.

Chung, C.C., Chen, T.S., Lin, LH., Lin, Y. C. \& Lin, C.M. (2016). Bankruptcy prediction using cerebellar model neural networks. International Journal of Fuzzy Systems, 18(2), 160-167.

Jarrow, R.A., Lando, D. \& Turnbull, S.M. (1997). A Markov model for the term structure of credit risk spreads. The Review of Financial Studies, 10(2), 481-523.

Kingyens, A.T., Paradi, J.C. \& Tam, F. (2016). Bankruptcy prediction of companies in the retail-apparel industry using data envelopment analysis. In Advances in Efficiency and Productivity. Springer, Cham: 299-329.

Kumar, P.R. \& Ravi, V. (2007). Bankruptcy prediction in banks and firms via statistical and intelligent techniques - A review. European Journal of Operational Research, 180(1), 1-28.

Leland, H.E. \& Toft, K.B. (1996). Optimal capital structure, endogenous bankruptcy, and the term structure of credit spreads. The Journal of Finance, 51(3), 987-1019.

Min, J.H. \& Lee, Y.C. (2005). Bankruptcy prediction using support vector machine with optimal choice of kernel function parameters. Expert Systems with Applications, 28(4), 603-614. 
Ng, S.T., Wong, J.M. \& Zhang, J. (2011). Applying Z-score model to distinguish insolvent construction companies in China. Habitat International, 35(4), 599-607.

Shin, K.S., Lee, T.S. \& Kim, H.J. (2005). An application of support vector machines in bankruptcy prediction model. Expert Systems with Applications, 28(1), 127-135.

Shumway, T. (2001). Forecasting bankruptcy more accurately: A simple hazard model. The Journal of Business, 74(1), 101-124.

Son, H., Hyun, C., Phan, D. \& Hwang, H.J. (2019). Data analytic approach for bankruptcy prediction. Expert Systems with Applications, 138, 112816.

Szetela, B., Mentel, G. \& Brożyna, J. (2016). In search of insolvency among European countries. Economic Research-Ekonomska Istraživanja, 29(1), 839-856.

Zhang, G., Hu, M.Y., Patuwo, B.E. \& Indro, D. C. (1999). Artificial neural networks in bankruptcy prediction: General framework and cross-validation analysis. European Journal of Operational Research, 116(1), 16-32.

Wu, C.H., Tzeng, G.H., Goo, Y.J. \& Fang, W.C. (2007). A real-valued genetic algorithm to optimize the parameters of support vector machine for predicting bankruptcy. Expert Systems with Applications, 32(2), 397408. 